\title{
Factors influencing $P$ terminal force in lead V1 of the ECG in hemodialysis patients
}

Andrzej Jaroszyński ${ }^{1,2}$, Anna Jaroszyńska ${ }^{3}$, Wojciech Dąbrowski ${ }^{4}$, Tomasz Zaborowski², Andrzej Stepulak ${ }^{5}$, Marek Itżecki ${ }^{6}$, Tomasz Zubilewicz ${ }^{6}$

\author{
${ }^{1}$ Institute of Medical Sciences, Jan Kochanowski University, Kielce, Poland \\ ${ }^{2}$ Department of Family Medicine, Medical University of Lublin, Lublin, Poland \\ ${ }^{3}$ Department of Cardiology, Medical University of Lublin, Lublin, Poland \\ ${ }^{4}$ Department of Anesthesiology and Intensive Care, Medical University of Lublin, \\ Lublin, Poland \\ ${ }^{5}$ Department of Biochemistry and Molecular Biology, Medical University of Lublin, \\ Lublin, Poland \\ ${ }^{6}$ Department of Vascular Surgery, Medical University of Lublin, Lublin, Poland
}

Submitted: 2 September 2015

Accepted: 17 November 2015

Arch Med Sci 2018; 14, 2: 257-264

DOI: https://doi.org/10.5114/aoms.2017.65926

Copyright $\odot 2017$ Termedia \& Banach

\section{Abstract}

Introduction: Atrial fibrillation (AF) is a highly prevalent arrhythmia in hemodialysis (HD) patients, and an HD session may be a trigger for AF episodes. An abnormal P-terminal force in lead V1 (PTFV1) may predict new-onset AF in HD patients. The aim of the study was to assess the influence of the HD process on PTFV1 and to evaluate possible factors influencing PTFV1 in a group of selected HD patients.

Material and methods: One hundred and fifty-three selected HD patients entered the study. Blood chemistry, electrocardiography, and impedance cardiography were evaluated before and after HD. Echocardiography was performed on the morning after dialysis. Abnormal PTFV1 was defined as PTFV1 $>40 \mathrm{~mm} \times \mathrm{ms}$.

Results: Abnormal PTFV1 was found in $35.3 \%$ of patients before dialysis and in $48.4 \%$ of patients after dialysis. The results of multiple regression analysis revealed that the independent predictors of pre-dialysis abnormal PTFV1 were: left atrial volume index $(p=0.002)$, left ventricular mass index $(p=0.014)$, and pre-dialysis thoracic fluid content $(p=0.021)$ values. The independent predictors of HD-induced abnormal PTFV1 values were larger differences between pre-dialysis and post-dialysis values of serum potassium $(p<0.001)$ and mean arterial pressure $(p=0.008)$.

Conclusions: Abnormal PTFV1 is prevalent in HD patients. The HD process adversely affects PTFV1 values. Pre-dialysis abnormal PTFV1 is mainly associated with structural heart abnormalities and hydration status. HD-induced abnormal PTFV1 is associated predominantly with serum potassium changes as well as HD-induced hypotension. Our results suggest possible risk factors for AF; however, their clinical significance needs to be confirmed in follow-up studies.

Key words: hemodialysis, atrial fibrillation, P-terminal force in lead V1, hydration status, potassium, hypotension.

\section{Introduction}

Chronic kidney disease is an independent risk factor for cardiovascular events [1-4]. Atrial fibrillation (AF) is a highly prevalent arrhythmia in hemodialysis (HD) patients. AF is estimated to occur in approximately

\author{
Corresponding author: \\ Andrzej Jaroszyński MD, PhD \\ Institute of Medical Sciences \\ Jan Kochanowski University \\ Aleja IX Wieków Kielc \\ 25-001 Kielce, Poland \\ Phone: +48 606968724 \\ E-mail: jaroszynskiaj@interia.pl
}


$18 \%$ of HD patients, which is 2 to 3 times higher than reported in the general population, even after adjustment for age, gender, and comorbidities $[1,5]$. Like in all other patients, the presence of AF is associated with increased mortality in HD patients $[5,6]$.

High prevalence of traditional risk factors can explain, at least partly, the high burden of AF in $\mathrm{HD}$ patients. However, risk factors for AF in HD patients do not mirror those reported in the general population. Some risk factors are specific to renal failure or related to the HD session itself $[2,5,7$, 8]. Recent studies have documented a distinct relationship between $\mathrm{AF}$ and the HD procedure, and that an HD session is considered a trigger for $A F$ episodes. The arrhythmogenic effect of the HD procedure is multifactorial in origin and is attributed, among other reasons, to changes of electrolyte concentrations, changes in acid base status, a rapid decrease in circulating blood volume, and secretion of catecholamines [5-7].

An electrocardiogram (ECG) carries important information about electrophysiological properties of the heart. $P$ wave parameters measured on ECG are commonly used as a noninvasive tool to evaluate left atrial (LA) abnormalities and carry important information about atrial electrophysiology, as well as structure and function. Abnormal P-terminal force in lead V1 (PTFV1) is a strong indicator of an enlarged, poorly functioning LA and is associated with increased risk of $A F$, stroke, left ventricular hypertrophy ( $\mathrm{LVH})$, heart failure as well as risk of death due to all-cause, cardiovascular (CV) disease, and ischemic heart disease mortality [9-12]. Recent studies have demonstrated that PTFV1 is prevalent in HD patients, and the presence of a PTFV1 $>0.04 \mathrm{~mm} \times$ ms predicts new-onset $A F$ in these patients [13-15]. To the best of our knowledge, there are no data in the literature on the influence of the HD process on PTFV1.

We designed this study to: (i) assess the influence of the HD process on PTFV1 and (ii) evaluate the possible factors influencing PTFV1 in a group of selected HD patients.

\section{Material and methods}

\section{Patients}

The study included adult chronic HD patients treated at two dialysis centers in Lublin. The exclusion criteria were: HD treatment less than 3 months, AF or flutter, and severe valvular disease. All patients gave written consent, and the studies were approved by members of the local ethics committees.

\section{Hemodialysis}

The HD patients were dialyzed three times weekly. Bicarbonate dialysate containing (in milli- moles per liter) 32 bicarbonate, $137-140$ sodium, 2.5-4.0 potassium (K), 0.50 magnesium and 1.25 or 1.5 calcium was used in all HD patients. During $\mathrm{HD}$, no medication was applied except heparin.

\section{Electrocardiography}

Surface 12-lead resting ECGs were recorded $10 \mathrm{~min}$ before and immediately after (not exceeding 15 min) a single HD session with a computer-based electrocardiograph (Cardiax, Imed Ltd., Hungary). Electrodes were not removed during the HD session. PTFV1 was defined as the duration in seconds of the terminal (negative) part of the $P$ wave multiplied by its depth in millimeters. Abnormal PTFV1 was defined as PTFV1 $>40 \mathrm{~mm} \times \mathrm{ms}$ [10]. The determinations of PTFV1 were made by the consensus of two observers, who were blinded to all of the patients' clinical data.

\section{Biochemical measurements}

The following parameters were measured by automated analyzers before dialysis: intact parathormone, albumin, C-reactive protein, cardiac troponin $\mathrm{T}, \mathrm{N}$-terminal pro-hormone brain natriuretic peptide, total cholesterol, high-density lipoprotein cholesterol and triglycerides. Low-density lipoprotein cholesterol was calculated using the Friedewald equation. Blood was obtained after at least $8 \mathrm{~h}$ fasting. The following parameters were measured by automated analyzers both before and after dialysis: serum sodium, K, calcium, phosphate, magnesium, hemoglobin ( $\mathrm{Hb})$. Post-dialysis blood samples were taken immediately after the end of an HD session (after $10-15 \mathrm{~s}$ of $50-100 \mathrm{ml} / \mathrm{min}$ blood flow).

\section{Impedance cardiography}

The impedance cardiography measurements were performed in patients $20 \mathrm{~min}$ before and immediately after (not exceeding $15 \mathrm{~min}$ ) a single HD session with a BioZ monitor (CardioDynamics, Int. Corp., San Diego, CA, USA). Sensors were placed as recommended by the manufacturer, and all measurements were performed according to the manufacturer's guidelines [13] as described in detail elsewhere [16]. The following parameters were determined: stroke index (SI), systemic vascular resistance index (SVRI), cardiac index (CI) and thoracic fluid content (TFC).

\section{Echocardiography}

Two-dimensional echocardiographic examination was performed using a $2.5-\mathrm{MHz}$ transducer by a cardiologist who was blinded to the clinical data of the study subjects. The left ventricular mass was indexed for body surface area to obtain 
the left ventricular mass index (LVMI). Left ventricle hypertrophy was defined by an LVMI over $131 \mathrm{~g} / \mathrm{m}^{2}$ in male or over $110 \mathrm{~g} / \mathrm{m}^{2}$ in female subjects [17]. Left ventricular ejection fraction (LVEF) was measured by Simpson's method. The LA volume was calculated with the biplane area method in apical 4-chamber views, and this was indexed for body surface area to obtain the LA volume index (LAVI) [18]. All echocardiographic measurements were performed on the morning after dialysis [17] according to the recommendations of the American Society of Cardiology.

\section{Statistical analysis}

Statistical analysis was carried out using Statistica version 10. Results were tested for normality by using the Kolmogorov-Smirnov test. When normally distributed, continuous variables were expressed as mean \pm SD, and as median and range when non-normally distributed. The statistical significance of the differences between pre- and post-dialysis results were compared using Student's $t$-test for paired data or using the Mann-Whitney U-test when appropriate. Categorical data were expressed as frequencies and percentages and were compared using the $\chi^{2}$ test. Multiple regression analysis was performed to estimate the potential influence of various factors on the PTFV1. Probability values of $p<0.05$ were accepted as significant.

\section{Results}

Of the total of $189 \mathrm{HD}$ patients initially identified, 28 (14.8\%) patients were excluded due to AF, 6 due to HD treatment less than 3 months, and 2 due to valvular disease. The remaining $153 \mathrm{HD}$ patients (81 females and 72 males), aged 44-87 years (mean: $67.97 \pm 9.18$ ), who remained on HD from 3 to 101 months (mean: $38.51 \pm 22.34$ ) entered the study. The causes of end-stage renal disease were diabetes $(n=66)$, glomerulonephritis $(n=32)$, hypertensive nephropathy $(n=11)$, obstructive nephropathy $(n=6)$, polycystic kidney disease $(n=5)$, chronic pyelonephritis $(n=5)$, and unknown/uncertain $(n=28)$. Out of 153 patients who qualified for the study, 122 (79.7\%) were taking angiotensin-converting enzyme inhibitors/angiotensin receptor blockers, 131 (85.6\%) $\beta$-blockers, 98 (64.1\%) statins and 104 (70.0\%) calcium blockers.

Before the HD, abnormal PTFV1 was found in 54 (35.3\%) of all patients. Of the 54 patients with abnormal pre-dialysis PTFV1, post-dialysis abnormal PTFV1 remained in 53 patients, whereas in 1 patient normalization of PTFV1 was observed. The HD process induced a significant increase in the PTFV1 value from $28.32 \pm 25.89 \mathrm{~mm} \times \mathrm{ms}$ to
$35.4 \pm 33.01 \mathrm{~mm} \times \mathrm{ms}(p=0.004)$. However, no significant increase in PTFV1 values was observed in HD patients in whom abnormal pre-dialysis PTFV1 values were observed (pre- vs. post-dialysis PTFV1 was $51.2 \pm 7.72$ and $53.9 \pm 7.05$ respectively, $p=0.205)$. After dialysis, abnormal PTFV1 was observed in 74 (48.4\%) patients. Of 74 patients with abnormal post-dialysis PTFV1, 21 had pre-dialysis PTFV1 values $<40 \mathrm{~mm} \times \mathrm{ms}$, and the $\mathrm{HD}$ process induced an increase of PTFV1 values. No differences were observed in PTFV1 between females and males either before or after dialysis. Statistical analysis was performed separately for patients with abnormal pre-dialysis PTFV1 and for patients in whom the HD process induced abnormal PTFV1 values. Baseline characteristics of patients with abnormal pre-dialysis PTFV1 as well as HD-induced abnormal PTFV1 values are shown in Tables I and II, respectively.

Patients with abnormal pre-dialysis PTFV1 were older $(p<0.001)$, more often had a history of myocardial infarction (MI) $(p<0.001)$, and had higher prevalence of diabetes $(p=0.011)$. With regard to echocardiographic parameters, patients with abnormal pre-dialysis PTFV1 values had higher left ventricular mass (LVM) $(p=0.001)$, LVMI $(p<0.001)$ and LAVI $(p<0.001)$ values, lower LVEF values $(p=0.010)$, and higher prevalence of LVH $(p=0.003)$. Additionally, patients with abnormal pre-dialysis PTFV1 values had lower $\mathrm{Hb}(p=0.015)$ and higher TFC values $(p=0.004)$ in comparison to patients with normal pre-dialysis PTFV1.

Patients in whom the HD process induced abnormal PTFV1 were on dialysis for longer ( $p=0.011)$, had a lower pre-dialysis SI value $(p=0.003)$, higher parathormone level $(p=0.008)$, larger differences between pre-dialysis and postdialysis values $(\Delta)$ of systolic blood pressure $(\Delta$ systolic BP) $(p=0.008)$, higher $\Delta$ mean arterial pressure $(\triangle \mathrm{MAP})(p=0.006)$, higher $\Delta$ potassium $(\Delta K)(p<0.001)$, higher $\Delta$ magnesium $(p=0.003)$, and higher $\triangle$ TFC values $(p=0.003)$.

The results of multiple regression analysis showing independent variables influencing pre-dialysis as well as dialysis-induced abnormal PTFV1 are presented in Tables III and IV, respectively. The independent predictors of pre-dialysis abnormal PTFV1 were LAVI, LVMI, and pre-dialysis TFC value. The independent predictors of HD-induced abnormal PTFV1 values were $\Delta K$ and $\triangle M A P$.

\section{Discussion}

Our study generated four major findings: (i) the prevalence of PTFV1 is high in HD patients, (ii) the HD process adversely affects PTFV1 values, (iii) pre-dialysis abnormal PTFV1 is mainly associated with structural heart abnormalities and hydration status, and (iv) HD-induced abnormal PTFV1 is 
Table I. Baseline characteristics of patients with abnormal and normal pre-dialysis PTFV1 values

\begin{tabular}{|c|c|c|c|c|}
\hline Parameter & $\begin{array}{l}\text { All patients } \\
(N=153)\end{array}$ & $\begin{array}{c}\text { Pre-dialysis } \\
\text { PTFV1(+) }(N=54)\end{array}$ & $\begin{array}{c}\text { Pre-dialysis } \\
\text { PTFV1(-) }(N=99)\end{array}$ & $P$-value \\
\hline Age [years] & $67.97 \pm 9.18$ & $72.96 \pm 8.42$ & $65.53 \pm 8.12$ & $<0.001$ \\
\hline HD vintage [months] & $38.51 \pm 20.34$ & $39.16 \pm 21.46$ & $38.23 \pm 20.06$ & 0.527 \\
\hline MI (\%) & 26.1 & 35.2 & 21.2 & $<0.001$ \\
\hline Diabetes mellitus (\%) & 42.5 & 48.1 & 39.4 & 0.011 \\
\hline Hypertension (\%) & 77.1 & 77.7 & 78.8 & 0.412 \\
\hline$\beta$-Blockers (\%) & 85.6 & 85.2 & 85.9 & 0.764 \\
\hline ACE/ARB (\%) & 79.7 & 79.6 & 79.8 & 0.821 \\
\hline Statins (\%) & 64.1 & 68.5 & 61.6 & 0.072 \\
\hline LVM [g] & $251.4 \pm 89.50$ & $284.9 \pm 78.4$ & $232.8 \pm 85.7$ & 0.001 \\
\hline LVMI $\left[\mathrm{g} / \mathrm{m}^{2}\right]$ & $143.3 \pm 43.64$ & $176.8 \pm 38.26$ & $125.0 \pm 45.13$ & $<0.001$ \\
\hline LVH (\%) & 64.7 & 72.2 & 60.6 & 0.003 \\
\hline $\mathrm{EF}(\%)$ & $58.31 \pm 6.34$ & $55.5 \pm 6.42$ & $59.8 \pm 6.23$ & 0.010 \\
\hline LAVI $\left[\mathrm{ml} / \mathrm{m}^{2}\right]$ & $36.29 \pm 9.82$ & $31.96 \pm 7.45$ & $38.6 \pm 9.12$ & $<0.001$ \\
\hline Hemoglobin [g/dl] & $11.45 \pm 1.11$ & $10.91 \pm 0.95$ & $11.75 \pm 1.14$ & 0.015 \\
\hline Total cholesterol [mg/dl] & $183.2 \pm 39.06$ & $189.8 \pm 38.99$ & $182.03 \pm 37.76$ & 0.325 \\
\hline LDL cholesterol [mg/dl] & $115.6 \pm 30.12$ & $117.6 \pm 29.16$ & $115.0 \pm 30.17$ & 0.612 \\
\hline HDL cholesterol [mg/dl] & $41.43 \pm 17.03$ & $40.62 \pm 17.44$ & $41.79 \pm 15.64$ & 0.698 \\
\hline Triglycerides [mg/dl] & $169.1 \pm 63.23$ & $159.9 \pm 70.43$ & $171.03 \pm 63.77$ & 0.542 \\
\hline $\mathrm{PTH}$, range $[\mathrm{pg} / \mathrm{ml}]$ & $382(0.0-1124)$ & $401(0.0-1124)$ & $379(0.0-825)$ & 0.412 \\
\hline Albumin $[\mathrm{g} / \mathrm{dl}]$ & $3.71 \pm 0.41$ & $3.65 \pm 0.46$ & $3.74 \pm 0.40$ & 0.476 \\
\hline CRP, range $[\mathrm{mg} / \mathrm{dl}]$ & $7.68(0.22-21.1)$ & $8.13(0.22-13.76)$ & $7.09(0.79-21.1)$ & 0.658 \\
\hline Troponin T, range $[\mu \mathrm{g} / \mathrm{l}]$ & $0.049(0.00-0.725)$ & $0.056(0.00-0.435)$ & $0.045(0.00-0.725)$ & 0.347 \\
\hline NT-proBNP $[\mathrm{fmol} / \mathrm{ml}]$ & $189.3 \pm 86.2$ & $196 \pm 82.24$ & $186.9 \pm 88.34$ & 0.101 \\
\hline Sodium $[\mathrm{mmol} / \mathrm{l}]$ & $137.9 \pm 2.66$ & $137.8 \pm 2.54$ & $137.9 \pm 2.59$ & 0.823 \\
\hline Potassium [mmol/l] & $5.79 \pm 0.78$ & $5.71 \pm 0.75$ & $5.81 \pm 0.70$ & 0.673 \\
\hline Magnesium [mmol/l] & $1.02 \pm 0.13$ & $1.00 \pm 0.19$ & $1.03 \pm 0.12$ & 0.348 \\
\hline Calcium $[\mathrm{mmol} / \mathrm{l}]$ & $2.48 \pm 0.25$ & $2.46 \pm 0.24$ & $2.48 \pm 0.23$ & 0.538 \\
\hline Phosphate $[\mathrm{mmol} / \mathrm{l}]$ & $2.24 \pm 0.75$ & $2.29 \pm 0.68$ & $2.23 \pm 0.74$ & 0.107 \\
\hline $\mathrm{MAP}[\mathrm{mm} \mathrm{Hg}]$ & $117.3 \pm 11.18$ & $120.1 \pm 10.97$ & $116.3 \pm 11.06$ & 0.423 \\
\hline Systolic BP [mm Hg] & $139.2 \pm 8.24$ & $137.4 \pm 8.12$ & $139.9 \pm 8.46$ & 0.572 \\
\hline Diastolic BP [mm Hg] & $75.31 \pm 4.44$ & $77.75 \pm 4.47$ & $74.56 \pm 4.43$ & 0.243 \\
\hline $\mathrm{SI}\left[\mathrm{ml} / \mathrm{bpm} / \mathrm{m}^{2}\right]$ & $40.32 \pm 8.03$ & $38.53 \pm 6.79$ & $40.90 \pm 8.45$ & 0.254 \\
\hline SVRI [dyn $\left./ \mathrm{s} / \mathrm{cm}^{-5} / \mathrm{m}^{2}\right]$ & $2681 \pm 567.6$ & $2954 \pm 547.2$ & $2597 \pm 604.4$ & 0.219 \\
\hline $\mathrm{Cl}\left[\mathrm{l} / \mathrm{min} / \mathrm{m}^{2}\right]$ & $3.11 \pm 0.51$ & $2.86 \pm 0.46$ & $3.23 \pm 0.51$ & 0.086 \\
\hline TFC $\left[\mathrm{kOhm}^{-1}\right]$ & $36.08 \pm 7.48$ & $39.02 \pm 6.67$ & $34.51 \pm 7.49$ & 0.004 \\
\hline
\end{tabular}

PTFV1(+) - patients with abnormal PTFV1 values, PTFV1(-) - patients with normal PTFV1 values, MI - myocardial infarction, ACE/ARB angiotensin-converting enzyme inhibitors/angiotensin receptor blockers, LVM - left ventricular mass, LVMI - left ventricular mass index, $L V H$ - left ventricular hypertrophy, EF - ejection fraction, LAVI - left atrial volume index, PTH - parathormone, CRP - C-reactive protein, $N T$-proBNP - N-terminal pro-hormone brain natriuretic peptide, MAP - mean arterial pressure, BP - blood pressure, SV - stroke volume, $S I$ - stroke index, SVRI - systemic vascular resistance index, CI - cardiac index, TFC - thoracic fluid content. 
Table II. Baseline characteristics of patients with HD-induced abnormal PTFV1

\begin{tabular}{|c|c|c|c|}
\hline Parameter & $\begin{array}{l}\text { HD-induced PTFV1 }(+) \\
(N=21)\end{array}$ & $\begin{array}{l}\text { The rest of HD patients } \\
\qquad(N=132)\end{array}$ & $P$-value \\
\hline Age [years] & $67.12 \pm 7.16$ & $68.09 \pm 8.86$ & 0.473 \\
\hline HD vintage [months] & $49.32 \pm 14.65$ & $36.79 \pm 18.96$ & 0.011 \\
\hline MI (\%) & 28.6 & 27.3 & 0.566 \\
\hline Diabetes mellitus (\%) & 38.1 & 46.2 & 0.213 \\
\hline Hypertension (\%) & 76.2 & 77.3 & 0.721 \\
\hline$\beta$-Blockers (\%) & 85.7 & 85.6 & 0.895 \\
\hline ACE/ARB (\%) & 76.2 & 80.3 & 0.419 \\
\hline Statins (\%) & 66.7 & 63.6 & 0.588 \\
\hline LVM [g] & $261.3 \pm 73.7$ & $249.8 \pm 85.9$ & 0.378 \\
\hline LVMI $\left[\mathrm{g} / \mathrm{m}^{2}\right]$ & $151.1 \pm 39.5$ & $142.1 \pm 44.4$ & 0.413 \\
\hline LVH (\%) & 71.4 & 63.6 & 0.308 \\
\hline $\mathrm{EF}(\%)$ & $59.14 \pm 5.06$ & $58.2 \pm 6.13$ & 0.642 \\
\hline LAVI $\left[\mathrm{ml} / \mathrm{m}^{2}\right]$ & $40.62 \pm 7.89$ & $35.65 \pm 9.11$ & 0.118 \\
\hline Hemoglobin [g/dl] & $11.89 \pm 0.87$ & $11.38 \pm 1.08$ & 0.422 \\
\hline Total cholesterol [mg/dl] & $176.8 \pm 30.1$ & $184.9 \pm 38.3$ & 0.333 \\
\hline LDL cholesterol [mg/dl] & $118.7 \pm 27.0$ & $114.7 \pm 29.5$ & 0.688 \\
\hline HDL cholesterol [mg/dl] & $33.15 \pm 13.9$ & $42.7 \pm 17.4$ & 0.121 \\
\hline Triglycerides [mg/dl] & $164.5 \pm 57.9$ & $169.9 \pm 62.77$ & 0.615 \\
\hline PTH, range $[\mathrm{pg} / \mathrm{ml}]$ & $596(356-1124)$ & $332(0.0-702)$ & 0.008 \\
\hline Albumin [g/dl] & $3.42 \pm 0.356$ & $3.76 \pm 0.412$ & 0.341 \\
\hline CRP, range $[\mathrm{mg} / \mathrm{dl}]$ & $9.76(0.96-18.5)$ & $6.99(0.22-21.1)$ & 0.236 \\
\hline Troponin T, range $[\mu \mathrm{g} / \mathrm{l}]$ & $0.058(0.00-0.689)$ & $0.043(0.00-0.725)$ & 0.346 \\
\hline NT-proBNP $[\mathrm{fmol} / \mathrm{ml}]$ & $207.0 \pm 77.4$ & $183.2 \pm 72.9$ & 0.189 \\
\hline Sodium predialysis [mmol/l] & $137.4 \pm 2.22$ & $138.0 \pm 2.62$ & 0.809 \\
\hline$\Delta$ sodium $[\mathrm{mmol} / \mathrm{l}]$ & $0.215 \pm 0.007$ & $0.213 \pm 0.009$ & 0.711 \\
\hline Potassium predialysis [mmol/l] & $6.17 \pm 0.69$ & $5.69 \pm 0.73$ & 0.201 \\
\hline$\Delta$ potassium $[\mathrm{mmol} / \mathrm{l}]$ & $1.99 \pm 0.016$ & $1.46 \pm 0.023$ & $<0.001$ \\
\hline Magnesium predialysis [mmol/l] & $1.03 \pm 0.17$ & $1.02 \pm 0.18$ & 0.456 \\
\hline$\Delta$ magnesium $[\mathrm{mmol} / \mathrm{l}]$ & $0.121 \pm 0.023$ & $0.081 \pm 0.015$ & 0.004 \\
\hline Calcium predialysis [mmol/l] & $2.40 \pm 0.24$ & $2.41 \pm 0.26$ & 0.729 \\
\hline$\Delta$ calcium $[\mathrm{mmol} / \mathrm{l}]$ & $-0.11 \pm 0.08$ & $-0.14 \pm 0.09$ & 0.462 \\
\hline Phosphate predialysis [mmol/l] & $2.08 \pm 0.69$ & $2.27 \pm 0.73$ & 0.324 \\
\hline$\Delta$ phosphate $[\mathrm{mmol} / \mathrm{l}]$ & $1.07 \pm 0.11$ & $1.12 \pm 0.14$ & 0.653 \\
\hline MAP predialysis [mm $\mathrm{Hg}$ ] & $119.1 \pm 9.76$ & $116.8 \pm 10.97$ & 0.397 \\
\hline$\Delta \mathrm{MAP}[\mathrm{mm} \mathrm{Hg}]$ & $6.82 \pm 2.25$ & $4.01 \pm 2.39$ & 0.004 \\
\hline Systolic BP predialysis [mm Hg] & $143.5 \pm 8.32$ & $138.9 \pm 8.97$ & 0.229 \\
\hline$\Delta$ systolic BP $[\mathrm{mm} \mathrm{Hg}]$ & $10.82 \pm 5.28$ & $6.68 \pm 6.14$ & 0.008 \\
\hline
\end{tabular}


Table II. Cont.

\begin{tabular}{|c|c|c|c|}
\hline Parameter & $\begin{array}{l}\text { HD-induced PTFV1(+) } \\
\qquad(N=21)\end{array}$ & $\begin{array}{l}\text { The rest of HD patients } \\
\qquad(N=132)\end{array}$ & $P$-value \\
\hline Diastolic BP predialysis [mm Hg] & $73.07 \pm 3.65$ & $75.95 \pm 4.07$ & 0.413 \\
\hline$\Delta$ diastolic BP $[\mathrm{mm} \mathrm{Hg}]$ & $-1.65 \pm 0.31$ & $-1.54 \pm 0.34$ & 0.521 \\
\hline SI predialysis $\left[\mathrm{ml} / \mathrm{bpm} / \mathrm{m}^{2}\right]$ & $34.12 \pm 7.43$ & $41.30 \pm 7.89$ & 0.003 \\
\hline$\Delta \mathrm{SI}\left[\mathrm{ml} / \mathrm{bpm} / \mathrm{m}^{2}\right]$ & $6.18 \pm 2.37$ & $7.05 \pm 2.76$ & 0.165 \\
\hline SVRI predialysis $\left[\mathrm{dyn} / \mathrm{s} / \mathrm{cm}^{-5} / \mathrm{m}^{2}\right]$ & $2834.1 \pm 501.7$ & $2658.2 \pm 555.9$ & 0.279 \\
\hline$\Delta \mathrm{SVRI}\left[\mathrm{dyn} / \mathrm{s} / \mathrm{cm}^{-5} / \mathrm{m}^{2}\right]$ & $-592.2 \pm 213.4$ & $-566.3 \pm 255.6$ & 0.411 \\
\hline $\mathrm{Cl}$ predialysis $\left[\mathrm{l} / \mathrm{min} / \mathrm{m}^{2}\right]$ & $3.01 \pm 0.37$ & $3.14 \pm 0.42$ & 0.358 \\
\hline$\Delta \mathrm{Cl}\left[\mathrm{l} / \mathrm{min} / \mathrm{m}^{2}\right]$ & $0.311 \pm 0.045$ & $0.299 \pm 0.049$ & 0.419 \\
\hline Body weight loss [kg] & $3.199 \pm 0.895$ & $2.882 \pm 1.273$ & $\underline{0.108}$ \\
\hline TFC predialysis $\left[\mathrm{kOhm}^{-1}\right]$ & $38.33 \pm 6.99$ & $35.97 \pm 7.04$ & 0.122 \\
\hline$\Delta \mathrm{TFC}\left[\mathrm{kOhm}^{-1}\right]$ & $8.87 \pm 3.25$ & $5.03 \pm 3.66$ & 0.003 \\
\hline
\end{tabular}

PTFV1(+) - patients with abnormal PTFV1 values, PTFV1(-) - patients with normal PTFV1 values, MI - myocardial infarction, ACE/ARB angiotensin-converting enzyme inhibitors/angiotensin receptor blockers, LVM - left ventricular mass, LVMI - left ventricular mass index, $L V H$ - left ventricular hypertrophy, EF - ejection fraction, $L A V I$ - left atrial volume index, PTH - parathormone, CRP - C-reactive protein, $N T$-proBNP - N-terminal pro-hormone brain natriuretic peptide, MAP - mean arterial pressure, BP - blood pressure, SV - stroke volume, $S I$ - stroke index, SVRI - systemic vascular resistance index, $\mathrm{Cl}$ - cardiac index, TFC - thoracic fluid content.

Table III. Factors influencing pre-dialysis abnormal PTFV1 estimated by multivariate stepwise regression analysis

\begin{tabular}{|lccccc|}
\hline $\begin{array}{l}\text { Dependent } \\
\text { variable }\end{array}$ & $\begin{array}{c}\text { Independent } \\
\text { variables }\end{array}$ & B & St. error & $\beta$ & $P$-value \\
\hline PTFV1 & LAVI & 0.497 & 0.029 & 0.343 & 0.002 \\
\cline { 2 - 6 } & LVMI & 11.23 & 6.61 & 0.295 & 0.014 \\
\cline { 2 - 6 } & Pre-dialysis TFC & 7.664 & 3.989 & 0.297 & 0.021 \\
\cline { 2 - 6 } & \multicolumn{5}{c}{ Model $\left(R=0.634, R^{2}=0.351\right)$} \\
\hline
\end{tabular}

Table IV. Factors influencing HD-induced abnormal PTFV1 estimated by multivariate stepwise regression analysis

\begin{tabular}{|lccccc|}
\hline $\begin{array}{l}\text { Dependent } \\
\text { variable }\end{array}$ & $\begin{array}{c}\text { Independent } \\
\text { variables }\end{array}$ & B & St. error & $\beta$ & $P$-value \\
\hline PTFV1 & $\Delta \mathrm{K}$ & 3.45 & 1.13 & 0.412 & $<0.001$ \\
\cline { 2 - 6 } & $\Delta \mathrm{MAP}$ & 5.76 & 2.38 & 0.396 & 0.008 \\
\cline { 2 - 6 } & \multicolumn{5}{c}{ Model $\left(R=0.560, R^{2}=0.314\right)$} \\
\hline
\end{tabular}

predominantly associated with $\mathrm{K}$ as well as a drop in blood pressure.

The results of our study are in agreement with the results of previous studies, which indicated that the prevalence of abnormal PTFV1 is high in HD patients [11, 12]. In our study the prevalence of pre-dialysis abnormal PTFV1 was $35.3 \%$ and was very similar to the prevalence (34\%) found by Nishi et al. [12]. Interestingly, Bilen et al. [11] found higher prevalence (66\%) of abnormal PTFV1 in a small group of HD patients without clinically significant CVD.

According to our knowledge, ours is the first study to show that the HD process adversely af- fects PTFV1 values. It indirectly indicates that an HD session may be a trigger for AF episodes. It is in agreement with the results of previous studies $[6,7,19]$, which indicated that the HD session increases the risk for AF. Moreover, recent studies have demonstrated that abnormal PTFV1 is associated with decreased LA functions [11], and may predict new-onset AF in HD patients [12].

The results of our study revealed that pre-dialysis abnormal PTFV1 values were associated with structural heart abnormalities and hydration status.

The re-entrant nature of AF requires areas of conduction delay to initiate and sustain arrhythmia, and pathological structural remodeling con- 
tributes to the development of AF [20]. Coronary artery disease and cardiomyopathy represented by echocardiographic evidence of structural heart disease form a possible arrhythmogenic pathway. Both LAVI and LVMI are well-known factors predisposing to AF in the general population [21] as well as in dialysis patients [19].

Hydration status is a potentially modifiable factor that affects the presence of pre-dialysis abnormal PTFV1. Myocardial stretch due to excessive volume overload results in electrophysiological changes in refractoriness and conduction, essential components of re-entry and proarrhythmia, and can induce arrhythmias. In HD patients, chronic fluid overload is a well-known factor leading to CV complications, such as myocardial dysfunction, hypertension, LVH, heart failure, arrhythmias, and cardiovascular mortality [8, 22]. Further studies are required to determine the possible TFC values that may induce abnormal PTFV1 values.

Our study revealed that dialysis-related functional abnormalities are also capable of inducing the presence of abnormal PTFV1.

The most likely mechanism through which changes in serum potassium induce abnormal PTFV1 is the influence of potassium on the cell membrane potential. The removal of $\mathrm{K}$ during $\mathrm{HD}$ is determined by the blood-dialysate concentration gradient, which generates diffusive-convective flows through the HD membrane, and affects the intra/extra $\mathrm{K}$ concentration ratio [23]. It is proposed that low potassium (potassium level drop) leads to cellular hyperpolarity, increases resting potential, increases atrial conduction time and hastens depolarization - all factors which predispose to the onset of re-entrant arrhythmias [8, 23-25]. Our results confirm that special attention should be focused on the intra-dialysis $K$ concentrations, and probably dynamic adjustment of dialysis bath $\mathrm{K}$ is a strategy that should be considered to reduce the arrhythmogenic effect of the HD process.

Intradialytic hypotension (IDH) is estimated to occur during $20-30 \%$ of HD sessions [26, 27]. In our study IDH defined as a decrease of MAP by $\geq 10 \mathrm{~mm} \mathrm{Hg}$ occurred in $17.4 \%$ of patients, and $\triangle M A P$ was an independent predictor of the HD-induced abnormal PTFV1. Two main factors predispose to IDH: rapid ultrafiltration and cardiac remodeling. Rapid ultrafiltration fails to elicit compensatory CV responses, such as vasoconstriction and rising cardiac output, while the combination of inadequate peripheral vascular tone and plasma refilling insufficiency leads to a drop of blood pressure. The geometry of the left ventricle in HD patients mostly presents as concentric hypertrophy, and the sequelae of cardiac remodeling might actively contribute to the development of IDH. Recent studies have demonstrated that IDH is strongly associated with cardiovascular morbidity and mortality, including arrhythmias [26]. The HD patients have been shown to have a reduced coronary flow reserve even in the absence of coronary artery stenoses. Intradialytic hypotension can causes systemic hypoperfusion, including myocardium $[26,27]$. This ischemic effect, though transient, may induce reversible myocardial dysfunction, which may potentially increase PTFV1; however, the ultimate cause remains unknown. Our study suggests that a drop in blood pressure should be especially avoided in patients prone to AF.

The present study has some important limitations. The main limitation is that there was no follow-up of our patients. This causes that both the prevalence of AF during follow-up and its relation with our results remain unknown. Therefore, our results can only indirectly suggest the potential factors associated with increased risk for AF in HD patients. The second limitation is the relatively small number of patients and the impossibility of controlling all possible factors that might influence PTFV1. Further studies are required to confirm our results as well as to determine their possible clinical importance in HD patients.

In conclusion, abnormal PTFV1 is prevalent in HD patients. Pre-dialysis abnormal PTFV1 is mainly associated with structural heart abnormalities and hydration status. HD-induced abnormal PTFV1 values are associated with serum $\mathrm{K}$ and blood pressure drop. Our results suggest only possible risk factors for AF in HD patients. However, their clinical significance needs to be confirmed in follow-up studies.

\section{Conflict of interest}

The authors declare no conflict of interest.

\section{References}

1. Zimmerman D, Sood M, Rigatto C, Holden R, Hiremath S, Clase C. Systematic review and meta-analysis of incidence, prevalence and outcomes of atrial fibrillation in patients on dialysis. Nephrol Dial Transplant 2012; 27: 3816-22.

2. Vincenti A, Passini E, Fabbrini P, Luise M, Severi S, Genovesi S. Recurrent intradialytic paroxysmal atrial fibrillation: hypotheses on onset mechanisms based on clinical data and computational analysis. Europace 2014; 16: 396-404.

3. Genovesi S, Fabbrini P, Pieruzzi F, et al. Atrial fibrillation in end stage renal disease patients: influence of hemodialysis on $\mathrm{P}$ wave duration and atrial dimension. J Nephrol 2015; 28: 615-21.

4. Soliman E, Prineas R, Go A, et al. Chronic Renal Insufficiency Cohort (CRIC) Study Group. Chronic kidney disease and prevalent atrial fibrillation: the Chronic Renal Insufficiency Cohort (CRIC). Am Heart J 2010; 159: 1102-7.

5. Buiten $M$, de Bie M, Rotmans J, et al. The dialysis procedure as a trigger for atrial fibrillation: new insights in 
the development of atrial fibrillation in dialysis patients. Heart 2014; 100: 685-90.

6. Jaroszyński A, Głowniak A, Sodolski T, Zaluska W, Widomska-Czekajska T, Książek A. Effect of haemodialysis on signal-averaged electrocardiogram P-wave parameters. Nephrol Dial Transplant 2006; 21: 425-30.

7. Tiffany T, Ambale Venkatesh B, Volpe G, et al. Associations of electrocardiographic P-wave characteristics with left atrial function, and diffuse left ventricular fibrosis defined by cardiac magnetic resonance: the PRIMERI Study. Heart Rhythm 2015; 12: 155-62.

8. Liu G, Tamura A, Torigoe K, et al. Abnormal P-wave terminal force in lead $V 1$ is associated with cardiac death or hospitalization for heart failure in prior myocardial infarction. Heart Vessels 2013; 28: 690-5.

9. Tereshchenko L, Shah A, Li Y, Soliman E. Electrocardiographic deep terminal negativity of the $\mathrm{P}$ wave in $\mathrm{V} 1$ and risk of mortality: the National Health and Nutrition Examination Survey III. J Cardiovasc Electrophysiol 2014; 25: 1242-8.

10. Eranti A, Aro A, Kerola T, et al. Prevalence and prognostic significance of abnormal $P$ terminal force in lead V1 of the ECG in the general population. Circ Arrhythm Electrophysiol 2014; 7: 1116-21.

11. Bilen Y, Cankaya E, Simsek Z, et al. Relationship between left atrial functions, P-terminal force and interatrial block in chronic haemodialysis patients. Eur Rev Med Pharmacol Sci 2015; 19: 767-71.

12. Nishi K, Fujimoto S, Hisanaga S, Ogawa O, Kitamura K. Electrocardiographic assessment of incident atrial fibrillation in hemodialysis patients. Ther Apher Dial 2013; 17: $16-23$.

13. BioZ ICG Monitor User Manual. San Diego, CA: CardioDynamics, 2001

14. Jaroszyński A, Wysokiński A, Bednarek-Skublewska A et al. The effect of a single dialysis session on spatial QRS-T angle in haemodialysis patients. Nephrol Dial Transplant 2010; 25: 3723-9.

15. Stewart G, Gansevoort R, Mark P, et al. Electrocardiographic abnormalities and uremic cardiomyopathy. Kidney Int 2005; 67: 217-26.

16. Zapolski T, Wysokiński A, Książek A, Jaroszyński A. Left atrial volume index and aortic stiffness index in adult hemodialysed patients - link between compliance and pressure mediated by endothelium dysfunction; a cross-sectional study. BMC Cardiovasc Disord 2012; 12: 100. doi: 10.1186/1471-2261-12-100.

17. Vazquez E, Sanches-Perales C, Garcia-Garcia F, et al Atrial fibrillation in incident dialysis patients. Kidney Int 2009; 76: 324-30.

18. Benjamin E, Chen P, Bild D, et al. Prevention of atrial fibrillation: report from a National Heart, Lung, and Blood Institute Workshop. Circulation 2009; 119: 606-18.

19. Tsang T, Gersh B, Appleton C, et al. Left ventricular diastolic dysfunction as a predictor of the first diagnosed nonvalvular atrial fibrillation in 840 elderly men and women. J Am Coll Cardiol 2002; 40: 1636-44.

20. Voroneau L, Covic A. Arrhythmias in hemodialysis patients. J Nephrol 2009; 22: 16-25.

21. Severi S, Grandi E, Pes C. Calcium and potassium changes during haemodialysis alter ventricular repolarization duration: in vivo and in silico analysis. Nephrol Dial Transplant 2008; 23: 1378-86.

22. Santoro A, Mancini E, London G, et al. Patients with complex arrhythmias during and after haemodialysis suffer from different regimens of potassium removal. Nephrol Dial Transplant 2008; 23: 1415-21.
23. Stefánsson B, Brunelli S, Cabrera C, et al. Intradialytic hypotension and risk of cardiovascular disease. Clin J Am Soc Nephrol 2014; 9: 2124-32.

24. Sniderman A, Solhpour A, Alam A, Williams K, Sloand J. Cardiovascular death in dialysis patients: lessons we can learn from AURORA. Clin J Am Soc Nephrol 2010; 5: 335-340.

25. Flythe J, Kimmel S, Brunelli S. Rapid fluid removal during dialysis is associated with cardiovascular morbidity and mortality. Kidney Int 2011; 79: 250-7.

26. Daugirdas J. Pathophysiology of dialysis hypotension: an update. Am J Kidney Dis 2001; 38: S11-7.

27. Chao C, Huang J, Yen C. Intradialytic hypotension and cardiac remodeling: a vicious cycle. Biomed Res Int 2015; 2015: 724147. doi: 10.1155/2015/724147. 